\title{
AVALIAÇÃO DO ESTADO DE CONSERVAÇÃO DE NASCENTES EM MICROBACIAS HIDROGRÁFICAS.
}

\author{
STATUS OF CONSERVATION EVALUATION OF SPRINGS IN WATERSHEDS.
} \author{
VALLE DIAS ${ }^{3}$ Gilda Carneiro FERREIRA ${ }^{4}$

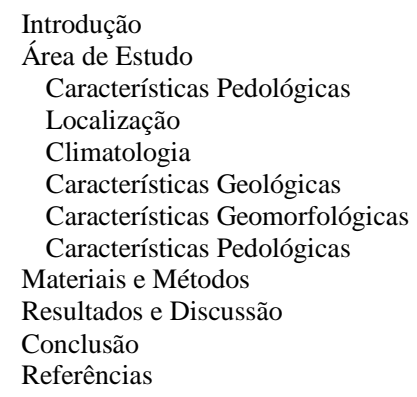

Juan Pedro PIERONI', Karina Grisólia RODRIGUES BRANCO², Graco Ribeiro do

1Pós-Graduação em Geociências e Meio Ambiente, Instituto de Geociências e Ciências Exatas, Universidade Estadual Paulista, Campus de Rio Claro. Av. 24 A, 1515 - Bela Vista. CEP 13506-900, Rio Claro (SP). Email: pieronibio@ hotmail.com; ${ }^{2}$ Pós-Graduação em Engenharia de Sistemas Agrícolas, Escola Superior de Agricultura "Luiz de Queiroz", Universidade de São Paulo. Avenida Pádua Dias, 11, Caixa Postal 09. CEP 13418-900, Piracicaba (SP). Email: karina_grb@ @otmail.com; ${ }^{3}$ Graduação em Engenharia Ambiental, Instituto de Geociências e Ciências Exatas, Universidade Estadual Paulista, Campus de Rio Claro. Av. 24 A, 1515 - Bela Vista. CEP 13506-900, Rio Claro (SP). Email: gracodias@ gmail.com;

${ }^{4}$ Departamento de Geologia Aplicada, Instituto de Geociências e Ciências Exatas, Universidade Estadual Paulista, Campus de Rio Claro. Av. 24 A, 1515 - Bela Vista. CEP 13506-900, Rio Claro (SP). Email: gildacf@ rc.unesp.br.

RESUMO - O estudo de nascentes em microbacias hidrográficas é um importante instrumento de gestão na conservação e preservação dos recursos hídricos visando à produção de água, tanto em quantidade quanto em qualidade. Diante desse desafio, o presente artigo avalia o estado de conservação das nascentes da microbacia do Córrego Ibitinga, localizada no município de Rio Claro, SP. A metodologia adotada abordou o estado de conservação com base em parâmetros macroscópicos de avaliação. Os parâmetros selecionados permitiram avaliar de maneira integrada, os impactos físicos, biológicos e socioeconômicos que afetam as nascentes. Com a aplicação do Índice de Impacto Ambiental em nascentes, os parâmetros foram mensurados e o tratamento estatístico dos dados permitiu a classificação das nascentes em cinco níveis de conservação: ótimo, bom, razoável, ruim e péssimo. Os resultados demostraram os parâmetros mais expressivos para os processos de degradação nas nascentes avaliadas e a frequência de ocorrência dos impactos em relação aos níveis de conservação. As nascentes apresentaram inúmeros aspectos de degradação, sejam eles por ação antropogênica direta ou indireta. Das 39 nascentes estudadas, $75 \%$ estão concentradas nas três piores classes. Os resultados permitiram concluir que as nascentes avaliadas apresentaram alto nível de degradação, e que o estado de conservação das nascentes é inerente à proximidade com estradas e ausência de proteção e de vegetação, sendo estes os impactos mais frequentes.

Palavras chave: Recursos hídricos; índice de impacto ambiental em nascentes; produção de água.

\begin{abstract}
The study of springs in hydrographic basin is an important instrument to the management of the conservation and preservation of water resource aiming water production. In face of this challenge, this article evaluates the state of conservation of springs from the watershed of Córrego Ibitinga, located in Rio Claro (SP). The methodology adopted analyzed the state of conservation based in the evaluation of macroscopic parameters. The parameters used allowed to evaluate, in an integrated mode, the physics, biologics and socioeconomic impacts on springs. Using the Index of Environment Impact at springs, the parameters measured and the statistic treatment of the data enabled the classification of the springs into five levels of conservation: great, good, reasonable, bad and poor. The results revealed the most expressive parameters for the degradation process at the springs studied and frequency of occurrence of impacts in relation to the levels of conservation. The springs indicated several aspects of degradation, due to direct or indirect anthropogenic action. From the 39 springs studied, $75 \%$ were concentrated in the three worst levels. The results enabled the conclusion which the springs showed high level of degradation, and that the state of conservation of springs is inherent to the proximity with roads and the absence of local protection and of vegetation, being those the most frequent impacts.
\end{abstract}

Keywords: Water resources; Index of environment impact at springs; water production.

\section{INTRODUÇÃO}

Frente aos atuais desafios existentes para garantir a disponibilidade de água às presentes e futuras gerações, o bom uso e a conservação dos recursos hídricos devem ser planejados e gerenciados dentro dos preceitos de sustentabi- lidade, visando garantir o abastecimento de água para as populações presentes e futuras.

A gestão desses recursos deve ser encarada como parte do seu processo de obtenção, visando preservar a disponibilidade e qualidade de água nos 
reservatórios de água superficiais e subterrâneos.

Considerando a microbacia hidrográfica como a menor unidade de gestão territorial, segundo a Lei n. 9.433 de 8 de janeiro de 1997, que tem entre os fundamentos da Política Nacional de Recursos Hídricos, a água como um bem de domínio público, dotado de valor econômico, cujos usos prioritários são o abastecimento humano e a dessedentação de animais e cuja gestão deve tomar como unidade territorial a bacia hidrográfica, que constitui-se fundamental para o planejamento, manejo e uso adequado do solo e da água (BRASIL, 1997).

Essa discussão torna-se essencialmente importante em estudos direcionados a conservação e ou recuperação de nascentes e cursos d'água. Conceitualmente, "nascente" é o termo que define um sistema ambiental em que o afloramento da água subterrânea ocorre naturalmente de modo temporário ou perene, integrando a rede de drenagem. Este processo é responsável, em parte, pela a entrada de energia no sistema e dependente da interceptação do nível freático pela topografia local (Felippe, 2009). A literatura pertinente exibe algumas propostas para a classificação de nascentes na tentativa de sistematizar as heterogeneidades intrínsecas entre elas. Em grande parte, essas metodologias abordam critérios ambientais monovariados, que consideram apenas um dos incomensuráveis aspectos inerentes às nascentes (Felippe \& Junior, 2014).

As tipologias mais utilizadas, associadas a estudos fluviais classificam as nascentes com base nas variações sazonais em perenes ou temporárias (Valente, 2005; Christofoletti,
1981), e ainda pela metodologia proposta por Meinzer (1927) que considera apenas a vazão média anual das nascentes. Entretanto outras linhas de estudos têm sido desenvolvidas buscando avaliar de maneira integrada os impactos físicos, biológicos e socioeconômicos no estado de conservação das nascentes, tendo como foco principal as microbacias hidrográficas (Pieroni et al., 2015; Christofoletti et al., 2015; Machi \& Cunha, 2007).

Deste modo, a identificação, a análise e a classificação das nascentes quanto ao seu estado de conservação, tornam-se importantes instrumentos na composição de estudos voltados ao gerenciamento de microbacias, fornecendo dados que subsidiem a tomada de decisão, a definição de áreas prioritárias à conservação e preservação e ainda, a locação de recursos.

Gomes et al. (2005); França Junior \& Villa (2013); Oliveira et al. (2013), utilizaram uma metodologia que considera os potenciais impactos ambientais a que estão sujeitas as nascentes, porém numa abordagem macroscópica de caráter qualitativo. Sobretudo perante a atribuição de pesos aos parâmetros avaliados, torna-se possível mensurar os principais fatores de degradação, sua frequência e intensidade de ocorrência.

Este artigo tem como objetivo apresentar o resultado do primeiro estudo sistemático das nascentes da microbacia do Córrego Ibitinga. A partir da análise dos dados obtidos, foram feitas considerações sobre as características ambientais e estado de conservação das nascentes avaliadas, dando ênfase aos processos de degradação e aos impactos a estes associados.

\section{ÁREA DE ESTUDO}

\section{Localização}

A microbacia do Córrego Ibitinga está localizada na porção centro-leste do estado de São Paulo, no município de Rio Claro como mostra a figura 1. Esta microbacia foi selecionada por ser uma importante tributária para o Ribeirão Claro, que é responsável por $40 \%$ do abastecimento de água para a cidade de Rio Claro (DAEE, 2017), e a jusante, um importante afluente do Rio Corumbataí, responsável por $80 \%$ do abastecimento da cidade de Piracicaba (SEMAE, 2017).

A microbacia do Córrego Ibitinga é dividida em alta, média e baixa microbacia, abrangendo uma área de 2.792 ha, dos quais 1.480 ha ou seja, 53\% da área total, encontra-se coberta pela Floresta Estadual Edmundo Navarro de Andrade (FEENA), uma Unidade de Conservação de Uso Sustentável que possui um importante papel no desenvolvimento sócio ambiental e cultural do município e região, sendo conhecida nacionalmente por ser a primeira área de cultivo de eucalipto (Eucalyptus sp.) do Brasil, datando do ano de 1911 (BRASIL, 2000).

\section{Climatologia}

O clima da área de estudo enquadra-se na classificação Cwa de Köppen como mesotérmico, com temperatura média no mês mais frio entre $3{ }^{\circ} \mathrm{C}$ e $18{ }^{\circ} \mathrm{C}$, e tropical de altitude, com inverno seco e temperatura média do mês mais quente com $22^{\circ} \mathrm{C}$ 
(CEAPLA, 2015). A precipitação média mensal para os meses mais secos (abril a setembro) de 46,6 mm e temperatura média do mês mais frio inferior a $11^{\circ} \mathrm{C}$. O verão é chuvoso, apresentando uma precipitação média mensal de $197 \mathrm{~mm}$ (outubro a março) e a temperatura média do mês mais quente chega a $30^{\circ} \mathrm{C}$. O índice pluviométrico médio anual é de $1549 \mathrm{~mm}$.

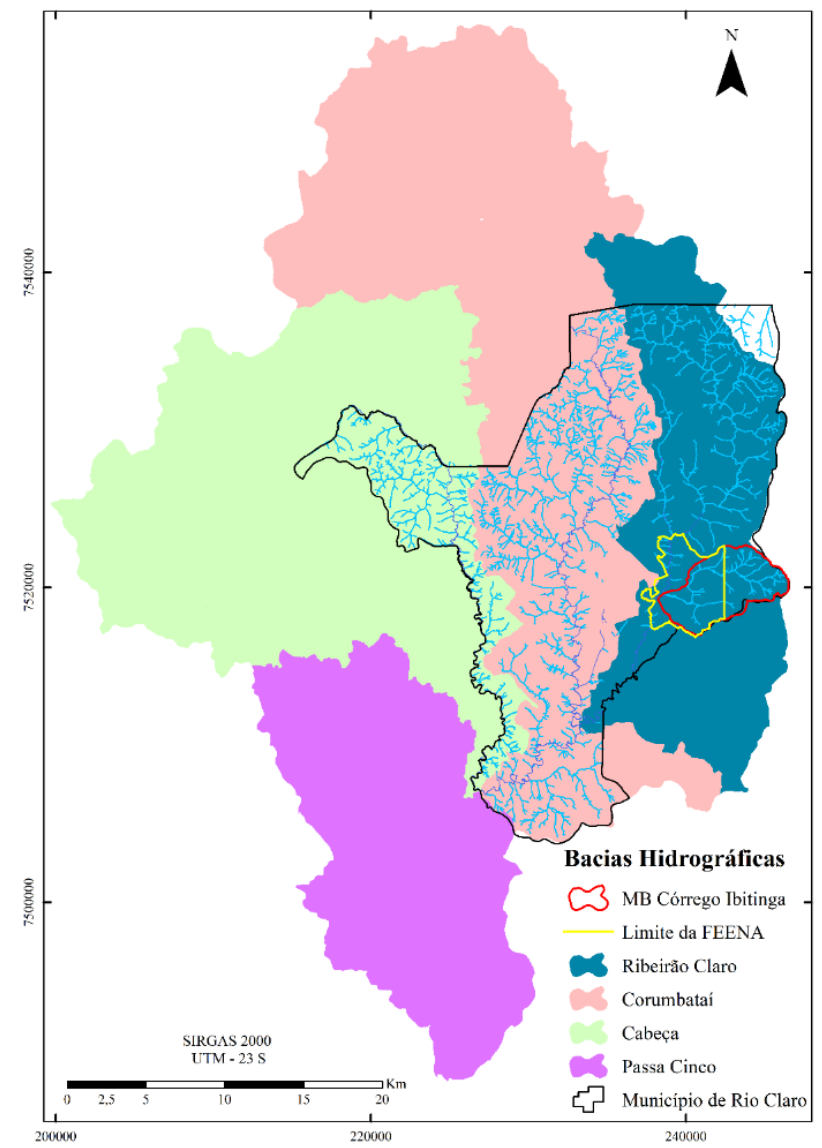

Figura 1 - Localização da área de estudo, no detalhe, a FEENA cobrindo parte da área da microbacia do Córrego Ibitinga, ambas situadas na sub-bacia do Ribeirão Claro.

\section{Características Geológicas}

Com relação às características geológicas da bacia do Córrego Ibitinga, estas estão vinculadas às Formações Corumbataí, Serra Geral, Pirambóia e Rio Claro (Cunha, 1997). Considerando à Geomorfologia, a área de estudo localiza-se na Depressão Periférica Paulista, na Zona do Médio Tietê (Almeida, 1974).

\section{Características Geomorfológicas}

Partindo do contexto geomorfológico, a bacia do Córrego Ibitinga possui altitudes entre 585 a $755 \mathrm{~m}$ com vertentes dominantemente convexas, vertentes côncavas e, em porção menos representativa, as vertentes retilíneas. A bacia apresenta, majoritariamente, declividades entre 6 a $12 \%$, principalmente na alta bacia; já nos setores de concavidade, as declividades predominam entre 12 a $20 \%$. As declividades mais elevadas, entre 20 a $40 \%$ e acima de $40 \%$, estão concentradas nos setores da alta bacia e, em menor proporção, nas áreas de concavidade do restante da bacia (Pinheiro, 2012).

\section{Características Pedológicas}

As características geológicas e geomorfológicas da área, bem como o clima local, condicionam a formação dos solos.

Concernente a isso, a área de estudo compõe-se em duas unidades principais referentes à abrangência de solos. O setor Norte, composto de solos com textura média a arenosa, e analiticamente distróficos e o setor Sul, composto de solos com textura argilosa a muito argilosa e analiticamente eutróficos

(INSTITUTO FLORESTAL, 2005).

Considerando a totalidade da bacia, a área de estudo é marcada pela predominância dos Argissolos, onde a declividade do relevo é mais acentuada, esta, se apresenta como o principal fator de diferenciação e formação dos solos menos desenvolvidos (Neossolos Lítólicos).

Ocorrem também Gleissolos nas faixas marginais do Córrego Ibitinga, no setor leste e na 
porção central da bacia, a ocorrência de Argissolos distróficos com textura mais grosseira é justificada como consequência dos materiais de origem: arenitos das formações Rio Claro e Pirambóia, siltitos e argilitos da formação Corumbataí (Pinheiro, 2012).

\section{METODOLOGIA}

A avaliação dos impactos ambientais pela observação das características macroscópicas das nascentes foi adaptada da metodologia proposta por Gomes et al. (2005).

Estes autores desenvolveram o Índice de Impacto Ambiental em Nascentes (IIAN), classificação que estabelece o estado de conservação em nascentes. A aplicação do método envolveu a análise de oito parâmetros macroscópicos, descritos na tabela 1. Cada parâmetro possui três diferentes atributos que devem ser observados e avaliados in situ. A cada atributo correspondente a um cenário a ser observado em campo, foi atribuído um peso que varia de um a três, sendo 1 para o cenário mais conservado e pesos 2 e 3 para cenários que apresentem maiores alterações em função das ações antrópicas. Os trabalhos de campo ocorreram nos anos de 2015 e 2016, durante os meses de outubro e novembro, caracterizando o fim da estação seca para a região.

Com base nos dados topográficos, hidrográficos e imagens de satélite, foi elaborada a logística de deslocamento em campo. Para a localização, identificação e georreferenciamento das nascentes foram realizadas incursões onde todas as drenagens foram percorridas de jusante para montante, dando-se relevância às tributações encontradas, seguindo-as até o ponto exato de exfiltração.

Tabela 1 - Parâmetros e atributos de avaliação e seus valores de mensuração.

\begin{tabular}{l|ccc}
\hline PARÂMETROS & PESO 3 & PESO 2 & PESO 1 \\
\hline Cor da água & Escura & Turva & Transparente \\
\hline Odor & Cheiro Forte & Cheiro Fraco & Sem Cheiro \\
\hline Lixo ao Redor & Muito & Pouco & Sem Lixo \\
\hline Vegetação & Degradada & Perturbada & Preservada \\
\hline Uso por animais & Presença & Apenas Marcas & Não Detectado \\
\hline Uso p/ humanos & Presença & Apenas Marcas & Não Detectado \\
\hline Proteção do Local & Sem Proteção & Com Proteção mas com & Com proteção e sem \\
\hline Prox. com estradas & Menos de 50 m & Entre $50 \mathrm{~m}$ e $100 \mathrm{~m}$ & Mais de $100 \mathrm{~m}$ \\
\hline
\end{tabular}

Fonte: Adaptado de Gomes et al. (2005).

Os pontos então foram marcados com o auxílio de um aparelho GPS, e plotados com auxílio de ferramentas SIG. O georreferenciamento das nascentes e elaboração do mapa temático foi feito com base em fotografias aéreas de alta resolução cedidas pela Emplasa, com resolução espacial de $1 \mathrm{~m}$ e cartas topográficas digitalizadas, disponibilizadas pelo IBGE na escala de 1:50.000. A partir dessas informações, com o auxílio de ferramentas SIG, foram extraídas a rede de drenagem e a delimitação da microbacia hidrográfica. Posteriormente os dados foram plotados e integrados à classificação gerada pelo índice aplicado.

Para geração do IIAN foi aplicada a soma dos pesos de cada parâmetro avaliado em campo. Esta soma permitiu classificar as nascentes em cinco classes, que representam o estado de conservação mediante os diferentes cenários avaliados, sendo a classe A o melhor cenário e E o pior estado de conservação (Tabela 2).

O mapa final apresenta a distribuição espacial das nascentes identificadas, bem como a sua classificação obtida na aplicação do IIAN

Tabela 2 - Classificação das nascentes quanto ao estado de conservação.

\begin{tabular}{l|l|l}
\hline CLASSE & Nível de Conservação & Pontuação Final \\
\hline A & Ótimo & Abaixo de 13 \\
B & Bom & Entre 13 e 15 \\
C & Razoável & Entre 16 e 18 \\
D & Ruim & Entre 19 e 21 \\
E & Péssimo & Entre 21 e 24 \\
\hline
\end{tabular}

Fonte: Adaptado de Gomes et al. (2005). 


\section{RESULTADOS E DISCUSSÃO}

Os resultados demostraram que grande parte das nascentes avaliadas apresentaram alto nível de degradação. Entretanto, vários pontos devem ser considerados para o entendimento da dinâmica de degradação das nascentes em microbacias. Os impactos mostraram-se permeáveis em relação aos níveis de classificação, podendo ocorrer em frequências diferentes e em mais de uma classe.
A coleta de dados em campo por meio da análise dos parâmetros macroscópicos, possibilitaram mensurar cada um dos parâmetros avaliados em relação à sua frequência de ocorrência, com isto, as nascentes foram agrupadas em classes, resultando em um índice com cinco níveis de classificação, cada um refletindo o nível de conservação das nascentes em relação aos parâmetros avaliados (Figura 2).

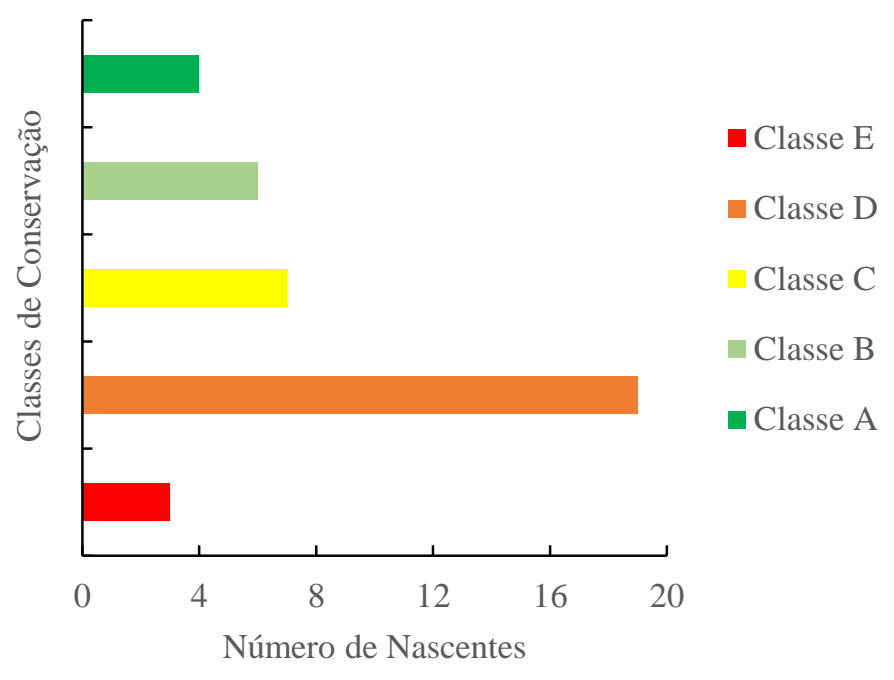

Figura 2 - Número de nascentes em cada classe do IIAN. A (ótimo), B (bom), C (razoável), D (ruim), E (péssimo).

Ao todo foram identificadas e georreferenciadas 39 nascentes, a maioria das nascentes encontram-se na cabeceira de drenagem na porção médio-alta da microbacia, circundada por matrizes de pastagem, cana de açúcar, silvicultura e matriz florestal nativa (Tabela 3).

Tabela 3 - Número de nascentes em relação a matriz de inserção.

\begin{tabular}{c|c}
\hline Matriz & $\mathbf{N}^{\mathbf{0}}$ Nascentes \\
\hline Pastagem & 20 \\
\hline Cana de açúcar & 17 \\
\hline Silvicultura & 1 \\
\hline Matriz Florestal & 1 \\
\hline
\end{tabular}

Com base nos resultados da aplicação do IIAN, e afim de contextualizar o estado de conservação de nascentes em relação à sua distribuição espacial em uma microbacia hidrográfica, a figura 4 apresenta um mapa temático contendo o georreferenciamento das nascentes na paisagem e a classificação destas em relação ao seu estado de conservação (Figura
3). Com base na figura 3 , verifica-se na porção sudeste, parte médio alta da microbacia, um conjunto de nascentes avaliado com altos níveis de degradação, enquadradas de acordo com o índice aplicado principalmente nas classes D e E. Estas nascentes encontram-se inseridas em matriz de pastagem, e em alguns casos na transição entre a pastagem e cana-de-açúcar.

À leste, na região de cabeceira, marcada pelo relevo mais acentuado, as nascentes apresentaram menores níveis de degradação, devido a ocorrência de vegetação nativa remanescente, em grande parte associada aos cursos de água, embora estejam inseridas em matriz de pastagem. No setor norte e noroeste, na parte média da microbacia, as nascentes encontram-se inseridas em matriz de cana-deaçúcar, enquadradas nas classes A, B, C e D. As nascentes em melhores níveis de conservação, destacam-se principalmente por estarem associadas a remanescentes de vegetação, mesmo estes, se apresentado perturbados ou vulneráveis a degradação, devido as pressões exercidas pelo uso do solo no entorno. 


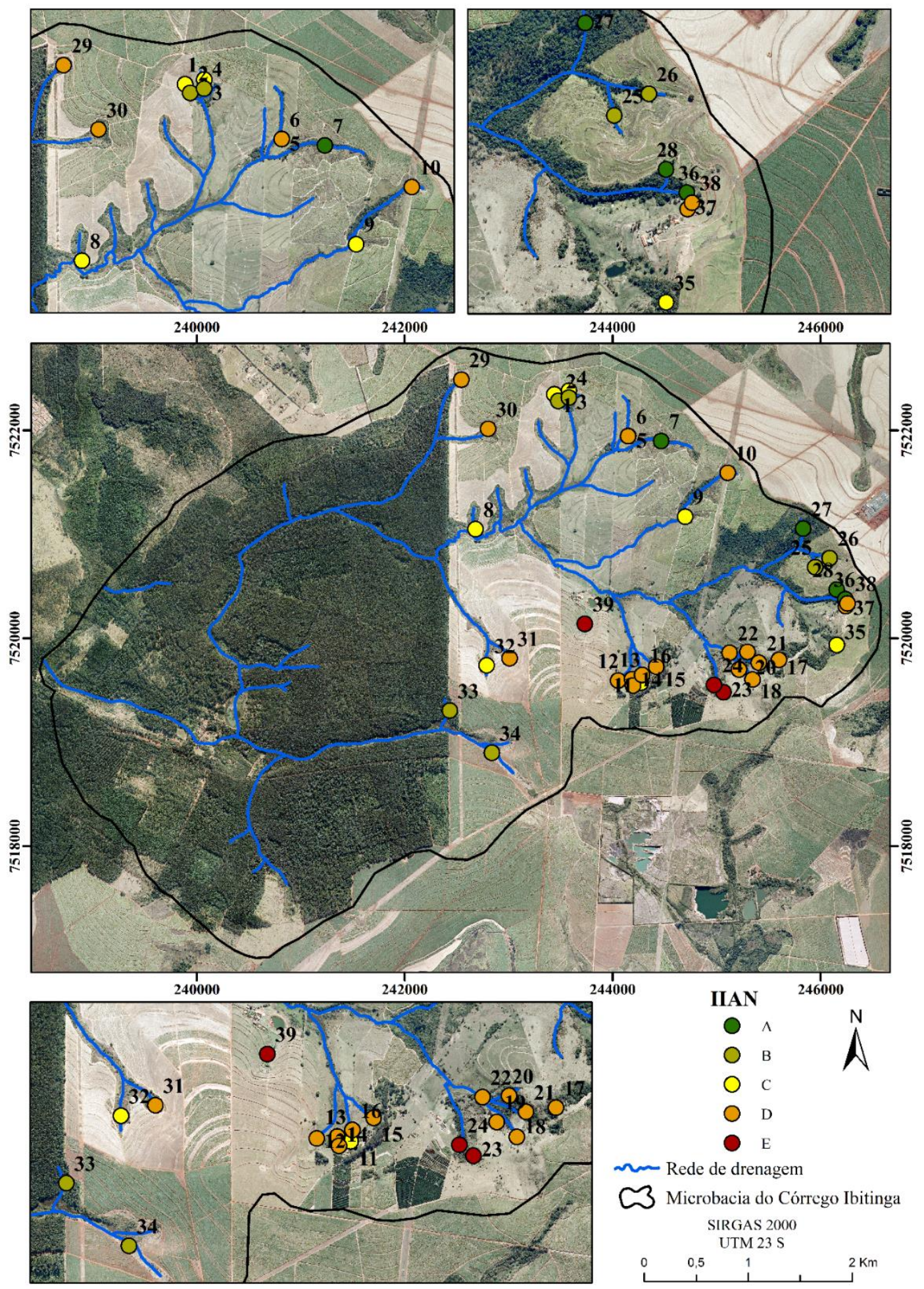

Figura 3 - Resultados obtidos na aplicação IIAN, na microbacia hidrográfica do Córrego Ibitinga.

Observando a frequência de ocorrência dos impactos em relação ao número total de nascentes avaliadas, verificou-se que os parâmetros se hierarquizam em relação as suas respectivas ordens de ocorrência, importância e ou vulnerabilidade, (Figura 4).

A avaliação do parâmetro proximidade com estradas mostrou que $69 \%$ das nascentes encontram-se a uma distância inferior a 50 metros da estrada mais próxima, estando em desacordo com estabelecido na legislação federal (BRASIL, 2012).

Em decorrência da proximidade com estradas, a vegetação também apresentou impactos expressivos no que se refere o seu estado de conservação, $72 \%$ das nascentes apresentaram alta degradação da vegetação, o que indica que impactos precedentes podem dar condições ao 
surgimento ou agravamento de demais impactos.

Gomes et al. (2005), em levantamento realizado em 16 nascentes da área urbana do município de Uberlândia, Minas Gerais, os autores verificaram que $56,25 \%$ das nascentes analisadas encontravam-se próximas a residências e estradas. Consequentemente a proteção nessas nascentes apresentou-se deficiente ou inexistente e segundo os autores, a degradação ambiental foi inversamente proporcional em nascentes que se localizam a maiores distâncias de residências e vias de acesso. Oliveira et al. (2013) avaliaram o estado de conservação de 28 nascentes em uma microbacia na qual está inserido o campus da Universidade Federal de Juiz de Fora MG. Segundo eles, o parâmetro proximidade de estradas e edificações foram os que apresentaram menor pontuação, portanto, mostrando maior vulnerabilidade às ações antrópicas.

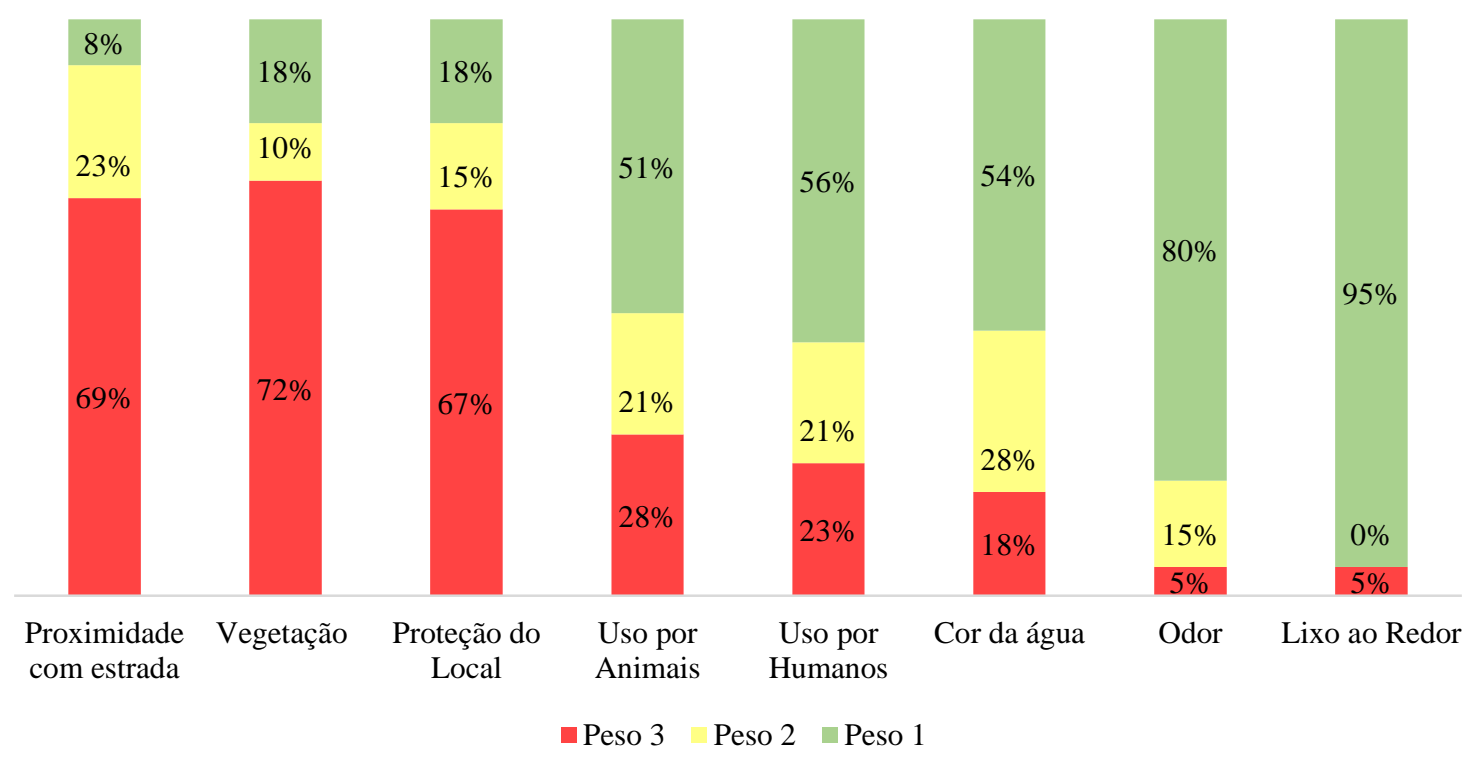

Figura 4 - Resultados percentuais dos parâmetros avaliados em relação aos pesos atribuídos.

França Junior \& Villa (2013), em estudo realizado em cabeceiras de drenagem na área urbana do município de Umuarama, noroeste do Estado do Paraná, relatam que $38 \%$ das nascentes por eles analisadas localizam-se a menos de 50 metros das residências e vias de acesso mais próximas e que a cobertura vegetal nessas nascentes apresentou alta degradação.

No trabalho realizado por Oliveira et al. (2013) para o parâmetro vegetação, nenhuma das nascentes avaliadas apresentou boas condições de conservação, deixando clara a vulnerabilidade das nascentes ao parâmetro avaliado.

Gomes et al. (2005) verificaram que 68,75\% das nascentes por eles avaliadas apresentaram valores negativos de preservação da vegetação. Segundo os autores, em geral foi observada a degradação da vegetação pela ocupação das áreas de APP, elevada dominância de espécies invasoras e em alguns casos, no entorno dos pontos de exfiltração, pela presença somente de pastagem.

Considerando os demais parâmetros hora discutidos e ainda, como apresentado na figura 3, $67 \%$ das nascentes não contém proteção adequada, seja pela proximidade com estradas ou degradação da vegetação ou ainda pela falta de isolamento por cerca ou outras estruturas de origem antrópica.

Conforme mencionam França Junior \& Villa (2013) em seu estudo, 25\% das nascentes não apresentavam proteção adequada, e embora as demais nascentes apresentem-se protegidas por cercas, o acesso ainda é facilitado.

A avaliação do parâmetro coloração da água também apresentou alterações, $18 \%$ das nascentes apresentaram coloração escura da água.

Considerando que as nascentes se encontram afastadas da área urbana, diferente das áreas estudadas pelos demais autores, não foi atribuído à coloração escura da água o lançamento de efluentes e sim a elevada turbidez provavelmente associada aos processos erosivos verificados em vários pontos, tanto no entorno das nascentes quanto em seus canais de drenagem. Segundo a 
figura 3, 20\% das nascentes apresentaram-se sem odor ou odor fraco, sobretudo, devido a não detecção de lançamento de efluentes nos trechos de canal percorridos, atribui-se a alteração de odor a decomposição natural de matéria orgânica, principalmente em trechos lênticos dos cursos d'água, exfiltrações com acumulo de água ou feições brejosas.

Nas nascentes avaliadas por Gomes et al. (2005), 25\% apresentaram alterações de coloração e odor da água.

Oliveira et al. (2013), entretanto, não observaram valores significativos para os tipos de uso avaliados, sobretudo, os autores relatam as alterações de coloração e odor da água, indicando uma potencial contaminação por esgoto em uma das nascentes por ele avaliadas.

Nas nascentes avaliadas por França Junior \& Villa (2013) no município de Umuarama, 25\% apresentaram alterações na coloração da água e ainda $38 \%$ que apresentaram alterações de odor. Os autores relatam que em alguns pontos a presença de óleos e espumas e elevada quantidade de lixo no entorno das nascentes.

Em relação aos tipos de uso, $49 \%$ das nascentes apresentaram evidências ou a presença de animais, tanto em cabeceiras de inserção como em canais de drenagem e em alguns casos, foi verificada a presença de grande número de animais de grande porte.

O uso por humanos foi verificado pela presença de estruturas e instrumentos de captação de água, sobre ou próximas às nascentes. Ao todo $44 \%$ das nascentes apresentam no mínimo evidências de uso por humanos (Figura 4).
Gomes et al. (2005) em seu trabalho observou que $68,75 \%$ das nascentes apresentaram evidencias de uso por animais e $75 \%$ evidências de uso por humanos.

Oliveira et al. (2013) não observou valores significativos para os tipos de uso avaliados, relatando apenas uma nascente classificada como uso esporádico por humanos.

Tendo em vista que as 39 nascentes avaliadas neste estudo estão localizadas distantes da área urbana, apenas $5 \%$ das nascentes avaliadas continham lixo no entorno, entretanto, a quantidade de lixo aferida foi elevada.

Gomes et al. (2005) menciona também a presença de lixo e entulho no entorno de grande parte das nascentes por ele avaliadas, destacando a quantidade elevada de lixo em algumas delas. Os autores atribuíram isso ao fato da não existência de proteção da APP, e ainda pela proximidade com residências, estradas ou vias de acesso.

Para Oliveira et al. (2013) a presença de lixo foi $o$ impacto ambiental mais observado, deixando claro, portanto, a vulnerabilidade das nascentes em relação ao acesso facilitado e a consequente poluição e contaminação da água. $\mathrm{O}$ autor defende que uma vez depositados, esses resíduos durante os períodos chuvosos, estes são carreados aos corpos hídricos influenciando direta e indiretamente na qualidade das águas.

Contudo, a análise sistemática para avaliação de impactos ambientais em nascentes abre caminhos para novos estudos, principalmente no que tange a abordagem espacial quantitativa dos aspectos ambientais e impactos ambientais intrinsicamente associados às ações antrópicas.

\section{CONCLUSÃO}

A análise dos parâmetros mostrou que a proximidade com estradas, degradação da vegetação, ausência de proteção foram os impactos mais relevantes para os cenários avaliados, mostrando-se expressivos também por preceder a ocorrência ou surgimento de demais impactos.

Os tipos de uso associados também se mostraram importantes, pois o uso por humanos e animais interfere diretamente na disponibilidade e qualidade da água, possuindo caráter agravante junto aos demais impactos mencionados.

Considerando o estado de conservação das nascentes do Córrego Ibitinga, $75 \%$ das nascentes apresentam-se em algum estágio de degradação, e mesmo os $25 \%$ aferidos como em bom e ótimo estado de conservação apresentaram vulnerabilidades em relação a alguns parâmetros avaliados.

O método de avaliação IIAN, mostrou-se eficiente do ponto de vista técnico e acadêmico, por proporcionar uma análise holística e sobretudo passível de mensuração.

O uso de ferramentas em ambiente SIG, também se mostrou relevante, permitindo uma interpretação da disposição espacial das nascentes na paisagem avaliada, corroborando para a exposição dos dados e entendimento dos resultados apresentados. 
A aplicação desta metodologia mostrou potencial em trabalhos que demandem estudos de diagnóstico e posteriores ações de planejamento, recuperação e gestão, no que tange a conservação dos recursos hídricos, mais especificamente em nascentes.

Diante da necessidade de se desenvolver metodologias confiáveis, representativas e economicamente viáveis para preservação dos recursos hídricos superficiais, este trabalho visou fornecer subsídios à tomada de decisão tanto no direcionamento e dimensionamento das ações e consequentemente na alocação dos recursos a serem investidos.

\section{REFERÊNCIAS}

ALMEIDA, F. F. M. de. Os fundamentos geológicos do relevo paulista. São Paulo: IGEOG, 1974.

BRASIL. Lei $\mathrm{n}^{\circ}$ 9.433, de 8 de janeiro de 1997. Institui a Política Nacional de Recursos Hídricos, cria o Sistema Nacional de Gerenciamento de Recursos Hídricos, regulamenta o inciso XIX do art. 21 da Constituição Federal, e altera o art. $1^{\circ}$ da Lei $\mathrm{n}^{\circ} 8.001$, de 13 de março de 1990, que modificou a Lei $\mathrm{n}^{\circ} 7.990$, de 28 de dezembro de 1989. Diário Oficial da República Federativa do Brasil, Poder Executivo, Brasília, DF, 08 de janeiro de 1997. Disp. em: http://www.planalto.gov .br/ccivil_03/leis/L9433.htm>. Acesso em: 22 mai. 2017.

BRASIL. Lei $\mathrm{n}^{\circ} 12.651$, de 25 de maio de 2012. Dispõe sobre a proteção da vegetação nativa; altera as Leis nos 6.938, de 31 de agosto de 1981, 9.393, de 19 de dezembro de 1996, e 11.428, de 22 de dezembro de 2006; revoga as Leis nos 4.771, de 15 de setembro de 1965, e 7.754, de 14 de abril de 1989, e a Medida Provisória no 2.166-67, de 24 de agosto de 2001; e dá outras providências. Diário Oficial da República Federativa do Brasil, Poder Executivo, Brasília, DF, 26 maio 2012. Disp. em: <http://www.planalto.gov.br/ccivil_03/_ato2011-

2014/2012/lei/112651.htm>. Acesso em: 20 jul. 2015.

BRASIL. Lei $\mathrm{n}^{\circ}$ 9.985, de 18 de julho de 2000. Regulamenta o art. 225, § 1o, incisos I, II, III e VII da CONSTITUIÇÃO Federal, institui o Sistema Nacional de Unidades de Conservação da Natureza e dá outras providências. Diário Oficial da República Federativa do Brasil, Poder Executivo, Brasília 19 de julho de 2000. Disp. em: < http://www.planalto.gov.br/CCivil_03/leis/L9985.htm>. Acesso em: 19 ago. 2015.

CEAPLA - CENTRO DE ANÁLISE E PLANEJAMENTO AMBIENTAL (CEAPLA). Atlas ambiental da bacia do Rio Corumbataí. Disponível em: <http://ceapla2.rc.unesp.br/atlas/ localizacao.php>. Acesso em: 19 ago. 2015

CHRISTOFOLETTI, A. Geomorfologia Fluvial. Editora Edgard Blücher, 1981.

CHRISTOFOLETTI, S.R; CONCEIÇÃO, F.T; SPATTI JUNIOR, E.P. Relações Hidroquímicas Aplicadas a Avaliação da Qualidade da Água na Bacia do Córrego Ibitinga, Rio Claro (SP). Geociências, São Paulo, v. 34, n. 2, p.224-237, 2015.

CUNHA, C. M. L. A. Quantificação e Mapeamento das Perda de solo por Erosão com Base na Malha Fundiária. 152 pp. 1997. Dissertação (Mestrado em Geografia). Instituto de Geociências e Ciências Exatas, Universidade Estadual Paulista, Rio Claro.

DAEE. Departamento Autônomo de Água e Esgoto: Sistema de tratamento de água. 2017. Disp. em: http://www.daae rioclaro.sp.gov.br/pagina.geral.php?pagina=tratamento-agua. Acesso em: 22 mai. 2017.

FELIPPE, M.F. Caracterização e tipologia de nascentes em Unidades de Conservação de Belo Horizonte-MG com base em variáveis geomorfológicas, hidrológicas e ambientais. Minas Gerais, 2009. Tese (Mestrado). Universidade Federal de Minas Gerais.
FELIPPE, M.F. \& JUNIOR, A.P.M. Desenvolvimento de uma tipologia hidrogeomorfológica de nascentes baseada em estatística nebulosa multivariada. Revista Brasileira de Geomorfologia, São Paulo, n. 3, p. 393 - 409, jul. 2014.

FRANÇA JUNIOR, P. \& VILLA, D.M.E.C. Análise macroscópica nas cabeceiras de drenagem da área urbana de Umuarama, região noroeste - Paraná/Brasil. Geografia Ensino \& Pesquisa, v. 17, n.1, p. $107-118,2013$.

GOMES, P.M.; MELO, C.; VALE, V.S. Avaliação dos impactos ambientais em nascentes na cidade de Uberlândia-MG: análise macroscópica. Sociedade \& Natureza, Uberlândia, p. 103 120, 2005.

INSTITUTO FLORESTAL / SMA. Plano de Manejo da Floresta Estadual Edmundo Navarro de Andrade. Vol. 1. Rio Claro; IF/SMA, 2005.

MACHI, D.A. \& CUNHA, C.M.L. Caracterização dos Elementos Físicos da Bacia do Córrego Santo Antônio (Rio Claro/SP). Sociedade e Natureza, Uberlândia, p. 139 - 151, 2007.

MEINZER, O.E. Large springs in the United States. U.S. Geological Survey Water-Supply, Paper 557. Washington D.C. 1927.

OLIVEIRA, M.C.P; OLIVEIRA, B.T.A.O; DIAS, M.M.N; SILVA, B.M; SILVA, S.V.B; FELIPPE, M.F. Avaliação macroscópica da qualidade das nascentes do campus da Universidade Federal de Juiz de Fora. Revista Geografia. v. 3, n. 1, 2013.

PIERONI, J.P.; BRANCO, K.G.R.; INACHVILI, I.; FERREIRA, G.C. Monitoramento sazonal da qualidade da água, na sub bacia hidrográfica do Córrego Água Limpa, em seu trecho afetado pela mineração de níquel, no município de Pratápolis, Minas Gerais. Revista Geociências, Rio Claro, v. 34, n. 3, 2015.

PINHEIRO, L.S. A Dinâmica Erosiva na Bacia Hidrográfica do Córrego Ibitinga - Rio Claro (SP): uma abordagem Empírico Dedutiva. Rio Claro. 2012. Tese (Doutorado). Instituto de Geociências e Ciências Exatas, Universidade Estadual Paulista.

SEMAE (Serviço Municipal de Água e Esgoto em Piracicaba). Relatório de Anual de Monitoramento de Qualidade de Água distribuída do ano de 2016. Disp. em: http://www.semaepiracicaba.sp.gov.br/admin/artigos/10090/A nual\%202017.pdf

VALENTE, O.F. \& GOMES, M.A. Conservação de nascentes: hidrologia e manejo de bacias hidrográficas de cabeceiras. Viçosa: Editora Aprenda Fácil, 210 p. 2005.

Submetido em 16 de junho de 2017 Aceito em 4 de setembro de 2018 